\title{
A prospective study to evaluate safety, efficacy and expulsion rate of post-partum insertion of intrauterine contraceptive device in a tertiary care centre
}

\author{
Sudha R. ${ }^{*}$, Nikita Singh ${ }^{2}$

\begin{abstract}
${ }^{1}$ Associate Professor, Department of Obstetrics and Gynecology, Cheluvamba Hospital, Mysore Medical College and
${ }^{2}$ Post Graduate Student, Department of Obstetrics and Gynecology, Cheluvamba Hospital, Mysore Medical College and Research Institute, Mysuru, India
\end{abstract} \\ Research Institute, Mysuru, India
}

Received: 15 January 2017

Accepted: 28 January 2017

\section{*Correspondence:}

Dr. Sudha R.,

E-mail: drsudhaobgmmcri@gmail.com

Copyright: (c) the author(s), publisher and licensee Medip Academy. This is an open-access article distributed under the terms of the Creative Commons Attribution Non-Commercial License, which permits unrestricted non-commercial use, distribution, and reproduction in any medium, provided the original work is properly cited.

\begin{abstract}
Background: The concept of contraception is not new, but its widespread application definitely is. Contraceptive availability is paramount for the health of women of reproductive age group. Among the variety of options available, female sterilization and IUCD are the most popular in developing countries. This study was conducted to assess the safety, incidence of complications, expulsion rates and willingness to continue at a 6 weeks' follow-up period; after insertion of $\mathrm{Cu}$ T $380 \mathrm{~A}$ within ten minutes of placental expulsion both in vaginal and $\mathrm{C}$-section deliveries.

Methods: Prospective study in the Department of Obstetrics and Gynaecology, Cheluvamba Hospital from a period of $1^{\text {st }}$ January 2016 to $31^{\text {st }}$ June 2016. All consenting antenatal cases including referrals, who fulfil all the inclusion criteria were included in the study. Expulsion rates at 6 weeks' follow-up were measured.

Results: Total women counselled were 462, accepted 50, declined 412, lost to follow up 3, followed up 47, expulsion 3 , bleeding 11 , string problems 5 , removal 8 , continuation 36 .

Conclusions: PPIUCD is demonstrably a safe and effective contraceptive with high retention rate in the hands of a skilled caregiver. Strategies to increase public awareness through media sources are the need of the hour. Training of healthcare providers, cash incentives to acceptor, motivator and provider would further promote its use in developing countries like India.
\end{abstract}

Keywords: Intra caesarean IUCD, Postpartum IUCD insertion, Post placental IUCD

\section{INTRODUCTION}

In the present era, an ever-increasing variety of effective methods is available for the regulation of fertility, none of which are completely exempt from side effects or potential dangers. However, there is no doubt that contraception poses far less risk than any pregnancy or abortion. Studies show that pregnancies taking place within 24 months of previous birth have higher risk of adverse outcome like abortion, premature labour, postpartum haemorrhage, low birth weight, fetal loss, and maternal death. ${ }^{1,2}$

More than 100 million women in developing countries would prefer to avoid pregnancy, but may not be using any form of contraception, due to the unmet need for contraception like unsatisfactory services, lack of information and fear about side effects of contraceptive methods. ${ }^{1}$ In India, it is estimated to be $15.8 \%$ by 
Demographic and Health surveys (DHS). IUCD is a long acting, reversible method of contraception, used by around $30 \%$ of couples. It is the most cost effective method of contraception if women are counselled properly. The post-partum insertion of an IUCD is likely to bring about a revolutionary change in contraceptive usage in India. With the introduction of Janani Shishu Suraksha Karyakram, free of cost emergency transportation facility and incentives for hospital delivery to ASHA/Anganwadi workers, labour rooms are attended by a large number of beneficiaries day by day. In developing countries, many women in far flung areas where health facilities are minimal and awareness is very less, pregnancy and delivery are the only times when they get an opportunity to visit a health set-up. High level of acceptance may be achieved by proper counselling during this period..$^{3,4}$

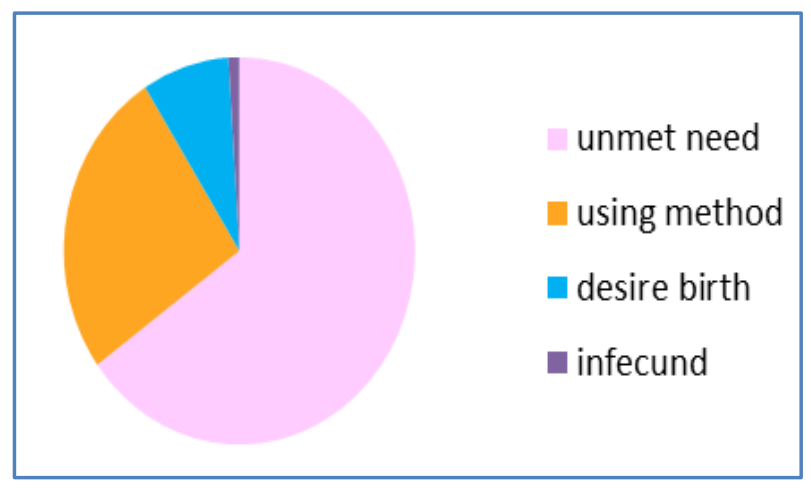

Figure 1: Unmet need among women in $1^{\text {st }}$ year postpartum.

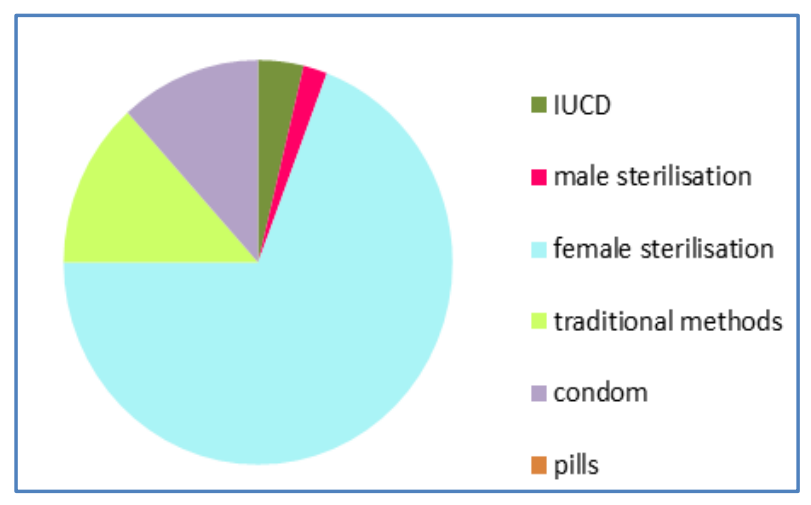

Figure 2: Contraceptive prevalence in India.

Source: USAID/ACCESS 2009. Family planning needs during the extended postpartum period in India. ${ }^{2}$

\section{METHODS}

\section{Source of the data}

Pregnant women attending hospital antenatal clinics (including referrals) in the Department of Obstetrics and Gynaecology, Cheluvamba Hospital, Mysore Medical college and Research institute.
The study was approved by the Institutional Ethics Committee, Mysore Medical College and Research Institute and Associated Hospitals, Mysuru, Karnataka, India.

It was a prospective study which was conducted from $1^{\text {st }}$ January 2016 to $31^{\text {st }}$ June 2016.

\section{Inclusion criteria}

- Woman delivering vaginally or by caesarian section, counselled for PPIUD insertion in the antenatal period or in latent labour and willing to participate in the study

- $18-40$ years old

- 28 - 42 weeks of gestation

- No infections

- $\mathrm{Hb} \geq 8 \mathrm{~g} / \mathrm{dl}$

\section{Exclusion criteria}

- Haemogloblin $<8 \mathrm{~g} / \mathrm{dl}$

- Postpartum Haemorrhage

- Pre-labour rupture of membranes $>18 \mathrm{~h}$

- Obstructed labour

- Distorted uterine cavity by fibroids or congenital malformations of uterus

- Pelvic infection

- Intra uterine fetal demise

- Temperature $>38^{\circ} \mathrm{C}$ during or after labor

Sample size consisted of all cases that met the inclusion criteria.

\section{Collection of data}

Study participants were recruited through hospital antenatal clinics including the referred cases, during the antenatal period and latent phase of labor. Various Postpartum contraception methods were routinely discussed at prenatal visits and the decision regarding the modality of choice was left to the couple. Those who fulfilled all the inclusion criteria and were willing for post-partum IUCD, i.e. insertion of $\mathrm{Cu}$ T $380 \mathrm{~A}$ within 10 minutes of placental expulsion after vaginal delivery (post placental) or Caesarean section (intra-caesarean PPIUCD) were included in the study.

\section{Insertion}

After delivery, routine active management of third stage of labour was done. ${ }^{3}$ Lady was counselled again for PPIUCD and informed consent taken. Instruments were arranged and parts painted and draped. Standard Universal Precautions and strict aseptic/no touch technique used at every step.

Perineum, labia and vaginal walls inspected for lacerations. Cervix was visualized by depressing 
posterior vaginal wall using a Sim's speculum. Cervix was then gently cleaned with Povidone Iodine cotton swabs. Anterior lip of cervix was held with ring forceps. IUCD (Cu-T 380 A) was positioned at the edge of a sterile Kelley's forceps in the sterile package. Gentle traction was applied on the cervical lip and IUCD inserted in the lower uterine cavity. Left hand was moved to the woman's abdomen to push the uterus upwards in order to straighten the utero-vaginal angle. IUCD was placed gently at the fundus. In case of $\mathrm{C}$-section, PPIUCD was placed inside the fundus through the lower segment incision. Uterine incision was then closed routinely. Care was taken not to push the threads into the os and not to include the threads in the sutures during uterine closure.

Cervix was examined and confirmed that IUCD / threads were not visible at the os.

\section{Safety analysis}

Safety was assessed on the basis of patients' complaints with respect to excess of bleeding/foul discharge/pain and perforation, if any, were noted.

\section{Follow up}

At the time of discharge from the hospital, women were advised to come for follow up after six weeks or anytime if they had any concerns. During follow up visits, women were asked especially for history of expulsion of IUCD, excessive bleeding, pain abdomen or abnormal discharge per vaginum. Pelvic examination was done and the findings were recorded. In per speculum examination if IUCD threads were long, they were cut $2 \mathrm{~cm}$ from external os. If threads of IUCD were not seen and there was no history of expulsion of IUCD, pelvic ultrasonography was done to note for misplaced IUCD. The patients wanting removal of $\mathrm{Cu} \mathrm{T}$ were considered as discontinuations.

\section{Efficacy analysis}

Expulsion rates at 6 weeks' follow-up were measured.

\section{RESULTS}

Total women counselled were 462, out of which 50 women accepted and consented for PPIUCD insertion while 412 declined. 3 cases were lost to follow up.

\section{Demographic variables}

Most of the subjects were aged between 20-30 years. Acceptance rate was higher in primigravidas. Education too had a positive impact on the acceptance of PPIUCD among the masses.

\section{Mode of delivery}

The mode of delivery i.e., vaginal or caesarean section, did not seem to play a major role in the rate of PPIUCD insertion or its acceptance/efficacy. Insertion of PPIUCD was easy in $100 \%$ of the cases while difficulty was encountered in insertion in 1 vaginally delivered case (easy insertion in $99.08 \%$ ). There were no complications noted during/ immediately post insertion.

\section{Follow-up}

Out of the 50 cases, 3 cases were lost to follow up. The remaining 47 cases were followed up after 6 weeks.

Out of the women followed up, 3 experienced spontaneous expulsion, 11 complained of increased bleeding per vaginum and 5 of them reported string problems. 8 women opted for removal of the intrauterine device, whereas 36 chose to continue.

Table 1: Demographic characteristics of the subjects (age).

\begin{tabular}{|lll|}
\hline Age group & No. $(\mathbf{n})$ & Percentage $(\%)$ \\
\hline$<20$ years & 11 & 22 \\
\hline 20-30 years & 38 & 76 \\
\hline$>30$ years & 1 & 2 \\
\hline Total & 50 & 100 \\
\hline Parity & No. $(\mathbf{n})$ & $\%$ \\
\hline Primi & 31 & 62 \\
\hline Multipara & 19 & 38 \\
\hline Total & 50 & 100 \\
\hline Education & No. $(\mathbf{n})$ & $\mathbf{\%}$ \\
\hline Illiterate & 8 & 16 \\
\hline Primary & 24 & 48 \\
\hline Secondary & 16 & 32 \\
\hline Higher & 2 & 4 \\
\hline Total & 50 & 100 \\
\hline
\end{tabular}

Table 2: Mode of delivery.

\begin{tabular}{|lll|}
\hline Mode & No. (n) & $\%$ \\
\hline Vaginal & 25 & 50 \\
\hline LSCS (Intra Caesarean) & 25 & 50 \\
\hline
\end{tabular}

5 women (10\%) among those inserted with PPIUCD had lost strings during first follow-up at 6 weeks. In 4 cases, strings were found at cervical canal. 1 case needed ultrasound and IUCD was confirmed to be in situ. One of those 5 insisted on removal. Other reasons for removal were family pressure, for which 4 women opted for IUCD removal, and bleeding/ pain abdomen which was the cause for removal in 1 woman. 2 women opted for a different method of contraception.

Kittur et al, concluded that the insertion of IUCD was easy in $99.52 \%$ of subjects after normal delivery. ${ }^{4}$ The 
position of the $\mathrm{Cu} \mathrm{T}$ was in situ in $94.78 \%$ of subjects, ultrasonogram was used in $24.76 \%$ to confirm location where threads were not visible in the vagina and in $6.19 \%$ of subjects the tip of IUCD was in the cervix which was pushed back into the uterus using artery forceps. It was expelled in $5.23 \%$ of patients. There was no case of perforation in this series.

Table 3: Discontinuations/expulsion/willingness to continue on follow up.

\begin{tabular}{|lll|}
\hline & No. (n) & $\%$ \\
\hline Bleeding & 11 & 22 \\
\hline String problems & 5 & 10 \\
\hline Expulsion & 3 & 6 \\
\hline Removal & 8 & 16 \\
\hline Continuation & 36 & 72 \\
\hline
\end{tabular}

\section{DISCUSSION}

Providing the PPIUCD immediately following delivery presents an opportunity for postpartum women to obtain a very convenient long acting method of contraception with only a few contraindications. Acceptance for this method was $10.8 \%$. A similar study by Kittur et al in 2012 showed an acceptance rate of $14 \% .{ }^{4}$ The main reasons for refusal were partner's non-involvement and refusal by family members, proving that couple's counselling in the antenatal period holds much more importance than the pregnant lady's alone. Second most important reason was fear of pain abdomen/bleeding per vaginum. Some believed that it interferes with sexual function while others chose some other method of contraception over IUCD.

Most of the subjects were aged between 20-30 years. $62 \%$ of them were primigravidas and $38 \%$ were multiparous. A similar study by Dr. Sujanendra in 2014 showed that acceptance was more common among primigravida clients $(20.73 \%)$ whereas in case of multiparous, it was $13.76 \% .^{5}$ However, it was contrary to that of the study by Grimes et al, where they found higher acceptance in multiparous clients. ${ }^{6}$

Katheit et al, stated that awareness about post-placental IUCD was significantly low as compared to interval IUCD $(5.79 \%$ versus $73.55 \%){ }^{7}$ Acceptance of PPIUCD was higher in the age group of $21-25$ years $(50.88 \%)$, para-2 $(35.76 \%)$, and educated $(65 \%)$ clients. Expulsion rate was $10.5 \%$.

Goswami et al, conducted a study where the total number of counselled women was 600 over the period of three months. ${ }^{8}$ Out of these only 400 women gave consent for PPIUCD insertion, 200 denied. 100 Lost follow-up only 300 women were followed-up. Among followed-up women 30 women had expulsion, 20 women had only bleeding problem, 20 women had only pain in abdomen, bleeding and abdominal pain together in found in 60 women, thread problem in 5 women and continuation on contraceptive method by 230 women, 70 women discontinued IUD because of bleeding, pain in abdomen, missing thread, family pressure etc.

Gupta et al, did a randomized study in which 150 women were recruited. ${ }^{9}$ Group A had 75 subjects and insertion of PPIUCD was done manually. Group B had 75 subjects and insertion was done with Kelly's placental forceps and there was no statistically significant difference in the mild discomfort during insertion by either technique. Time taken for insertion was significantly lower in group A. The combined expulsion rate (spontaneous complete expulsion and partial expulsion) at the end of 6 months was $11.9 \%$ in group A and $10.5 \%$ in group B (not statistically significant). Pain (16\% in group A and $12 \%$ in group B) was the most common problem encountered by IUD users followed by menstrual problems $(10.7 \%$ in group A and $8 \%$ in group B).

Gujju et al, counselled a total of 4209 women of which $780(18.5 \%)$ women accepted the method, 3429 declined. ${ }^{10}$ Out of the 780 cases, 764 came for follow up, and 16 were lost to follow up, spontaneous expulsion was seen in $2(0.2 \%)$ cases, removal was done on request in 1 case and continuation was seen in $761(97.56 \%)$ women.

S. Mishra, counselled a total of 3209 women out of which 564 accepted (Primigravida 20.73\%, multiparous $13.76 \%), 130$ were lost to follow up..$^{5}$ Out of 434 $(59.98 \%)$ cases followed up, 190 developed complications like bleeding $23.5 \%$, expulsion $6.4 \%$, string problem $8.69 \%$. 42 women opted for removal while 352 continued the IUCD use.

The PPIUCD expulsion rates were similar to a multi nation study by Tatum et al at the end of 1 month, Belgium: $4 \%$, Chile: $7 \%$, Philippines: $19 \% .{ }^{11}$ At the end of 12 months, the rates were comparable in the former two countries, whereas expulsion increased to $27 \%$ in Philippines.

Expulsion rate of post placental PPIUCD in a study done in china by Chi et al $9.5-12.5 \%$ which was significantly lower than post-partum IUCD: $25-30 \% .^{12}$

\section{CONCLUSION}

$\mathrm{Cu} \mathrm{T} 380 \mathrm{~A}$ Insertion at 10 minutes after placental delivery is a safe, convenient, cost effective, reversible and long term birth spacing method. Given the low rate of return for interval insertion, immediate placement may be preferable in the developing countries.

Though some studies have indicated that expulsion rates appear to be higher than with interval insertion- this is more applicable for developing countries where delivery may be the only time when a healthy woman comes into contact with health care providers and the chances of returning for contraceptive advice are uncertain. The 
expulsion rates would be minimal if it is inserted by a trained provider and placed at the fundus. It is important to arrange for training on PPIUCD in order to increase knowledge and skills among healthcare providers.

This will also further promote PPIUCD use and aid in reduction of the expulsion rates. The government schemes like Janani Suraksha Yojana (JSY) is an opportunity to add PPIUCD into family planning program.

\section{Funding: No funding sources}

Conflict of interest: None declared

Ethical approval: The study was approved by the Institutional Ethics Committee

\section{REFERENCES}

1. Ross JA, Winfrey W. Contraceptive use, intention to use and unmet needs during the extended postpartum period. Int family planning perspectives. 2001;27(1):20-27.

2. Jhpiego BM. ACCESS, Family planning initiative [ACCESS-FP], 2009. 4p. (USAID associative cooperative agreement number GPO-A-00-0500025-0). Available at: https://www.glowm.com/ pdf/ Global\% 20PPIUD\%20 Reference\% 20Manual.pdf.

3. PPIUCD reference manual. Family planning division, Ministry of health and family welfare, Govt. of India. 2010.

4. Sahaja K, Kabadi YM. Enhancing contraceptive usage by post placental IUCD insertion with evaluation of safety, efficacy and expulsion. Int $\mathrm{J}$ Reprod Contracept Obstet Gynecol. 2012;1(1):26-32.

5. Mishra S. Evaluation of safety, efficacy and expulsion of post placental and intra caesarean insertion of intra uterine contraceptive device. J Obstet Gynaecol India. 2014;64(5):337-43.
6. Grimes D, Schulz K, van Vliet H, Stanwood N. Immediate post-partum insertion of intrauterine devices. Cochrane Database Syst Rev. 2001;(2):CD003036.

7. Katheit G, Agarwal J. Evaluation of PPIUCD in terms of awareness, acceptance and expulsion in a tertiary care centre. Int J Reprod Contracept Obstet Gynecol. 2013;2(4):539-43.

8. Goswami G, Yadav K, Patel A. A Prospective study to evaluate safety, efficacy and expulsion rate of post placental insertion of intra uterine device. J of Evolution of Med and Dent Sci. 2015;4(56):9769-74.

9. Gupta N, Sinha R, Prateek S, Mangal A. A randomized study for two techniques of immediate post-partum intrauterine contraceptive device insertion in India. Int $\mathrm{J}$ Reprod Contracept Obstet Gynecol. 2014;3(2):398-402.

10. Gujju RLB, Prasad U, Prasad U. Study on the acceptance, complications and continuation rate of post-partum family planning using the post placental intrauterine contraceptive device among women delivering at a tertiary care hospital. Int J Reprod Contracept Obstet Gynecol. 2015;4(2):388-91.

11. Tatum HJ, Beltran RS, Ramos R, Van Kets H, Sivin I, Schmidt FH. Immediate post placental insertion of GYNE-T 380 and GYNE-T 380 postpartum contraceptive devices: randomized study. Am J Obstet Gynecol. 1996;175(5):1231-5.

12. Chi IC. Postpartum IUCD insertion: timing, route, lactation and uterine perforation. In: Bardin CW, Mishell DR Jr. eds. Proceedings from the fourth international conference on IUDs. London: Butterworth-Heineman; 1994:219-27.

Cite this article as: Sudha R, Singh N. A prospective study to evaluate safety, efficacy and expulsion rate of post-partum insertion of intrauterine contraceptive device in a tertiary care centre. Int J Reprod Contracept Obstet Gynecol. 2017;6:814-8. 